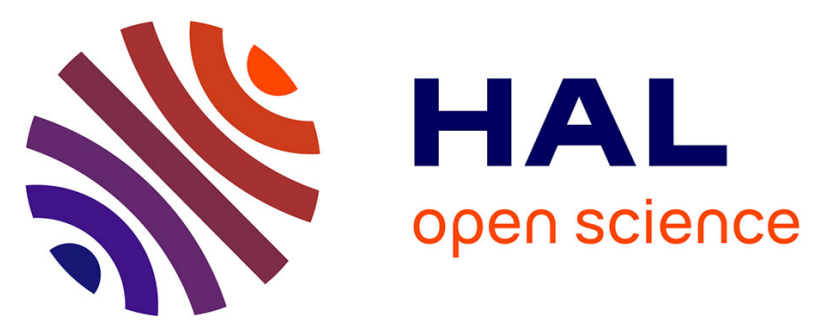

\title{
Using remotely sensed data to estimate area-averaged daily surface fluxes over a semi-arid mixed agricultural land
}

\author{
Ghani Chehbouni, Joost Hoedjes, Julio-Cesar Rodriquez, Chris J. Watts, \\ Jaime Garatuza, Frédéric Jacob, Yann H. Kerr
}

\section{To cite this version:}

Ghani Chehbouni, Joost Hoedjes, Julio-Cesar Rodriquez, Chris J. Watts, Jaime Garatuza, et al.. Using remotely sensed data to estimate area-averaged daily surface fluxes over a semiarid mixed agricultural land. Agricultural and Forest Meteorology, 2008, 148 (3), pp.330-342. 10.1016/j.agrformet.2007.09.014 . hal-02668104

\section{HAL Id: hal-02668104 \\ https://hal.inrae.fr/hal-02668104}

Submitted on 5 Nov 2021

HAL is a multi-disciplinary open access archive for the deposit and dissemination of scientific research documents, whether they are published or not. The documents may come from teaching and research institutions in France or abroad, or from public or private research centers.
L'archive ouverte pluridisciplinaire HAL, est destinée au dépôt et à la diffusion de documents scientifiques de niveau recherche, publiés ou non, émanant des établissements d'enseignement et de recherche français ou étrangers, des laboratoires publics ou privés.

\section{()ㅜ(1)}

Distributed under a Creative Commons Attribution - NonCommerciall 4.0 International 
Using remotely sensed data to estimate area-averaged daily surface fluxes over a semi-arid mixed agricultural land.

\author{
Chehbouni Abdelghani ${ }^{1}{ }^{*}$, Joost. C. B. Hoedjes ${ }^{1}$, Julio-Cesar Rodriquez ${ }^{2}$, Chris J. \\ Watts ${ }^{2}$,Jaime Garatuza ${ }^{3}$, Frederic Jacob ${ }^{4}$, and Yann H. Kerr ${ }^{1}$ \\ ${ }^{1}$ CESBIO/IRD, UMR CNES-CNRS-IRD-UPS, Toulouse , France \\ 2 UNISON, Hermosillo, Sonora, Mexico \\ 3 ITSON, Ciudad Obregón, Sonora, Mexico \\ ${ }^{4}$ LISAH/IRD, Montpellier, France
}

*corresponding author

Email: Ghani.Chehbouni@cesbio.cnes.fr

Address: CESBIO-UMR5126, CNES-CNRS-IRD-UPS

bpi 2801, 18 AVENUE EDOUARD BELIN.

31401, TOULOUSE, CEDEX9-FRANCE.

Tel: 00335615581 97, Fax 0033561558501. 


\section{Abstract}

Optical remote sensing has been widely used for diagnostics of land surface atmosphere exchanges, including evapotranspiration (ET). Estimating ET now benefits from modeling maturity at local scale, while ongoing challenges include both spatial and temporal issues: influences of spatial heterogeneities on non linear behavior when upscaling and extrapolation of instantaneous estimates at satellite overpass to the daily scale. Both issues are very important when using remote sensing for managing water resources, especially in agriculture. The two main contributions of the current study are first the examination of the diurnal behavior of evaporative fraction (EF) and available energy (AE) over heterogeneous agricultural land surfaces, and second presenting a simple approach to derive area-averaged daily ET under such conditions. Area-averaged fluxes are expressed using the same equations as those used over homogeneous areas, but whose arguments are effective expressions of the local parameters involved. Next, heuristic formulations are proposed to estimate the diurnal courses of $\mathrm{EF}$ and $\mathrm{AE}$, by combining diurnal meteorological information available from observation networks (or weather forecasts) with instantaneous estimates at satellite overpass obtained from a simple energy balance model. These investigations were conducted using ground based data collected in the semi-arid Yaqui valley, north-western Mexico, over three adjacent agricultural fields which different crops and soil moisture conditions. This approach accurately reproduced the diurnal course of ET. However, these promising results have to be confirmed using actual satellite and operational meteorological data. This work is the subject of ongoing investigations.

Keywords: semi-arid regions; remote sensing; evapotranspiration; evaporative fraction; eddy covariance; aggregation. 


\section{INTRODUCTION}

During the past decades, considerable effort has been made in the use of remote sensing to improve our understanding of feedback mechanisms between landsurface and atmospheric processes. Emphasis has been mainly directed towards a better estimation of evapotranspiration (ET) and its spatial variability, with special focus on the impact of spatial heterogeneity (Betts et al., 1997; Courault et al., 2005; Hipps and Kustas, 2000; Moran, 2004; Moran et al., 1994; Olioso et al., 2005; Porporato et al., 2004; Walker and Houser, 2004). Additionally, accurate estimates of ET, especially over agricultural regions in arid and semi-arid climate, are of crucial importance for sound water resource management (Seguin and Itier, 1983). Indeed, irrigation consumes more than $85 \%$ of the available water in arid and semi-arid regions (Chehbouni et al., 2007a). However, the dynamics at the typical spatial extent of major agricultural fields cannot be captured with coarse resolution satellite sensors such as MODIS or AVHRR and remotely sensed pixels at these low spatial resolutions are likely to contain mixed fields (Kustas et al., 2004). This is a classical problem in hydrological science, i.e., a discrepancy between the scale of satellite observation and that at which the processes need to be described (McCabe and Wood, 2006).

In this context, substantial effort of the earth science community has been directed during the past decade toward the investigation of aggregation and disaggregation problems from both theoretical and experimental perspectives (Aman et al., 1992; Avissar, 1998; Chehbouni et al., 1995; Kustas and Norman, 1997; Lhomme, 1992; Lhomme et al., 1994; McNaughton, 1994; Merlin et al., 2006; Merlin et al., 2005; Moran et al., 1997; Njoku et al., 1996; Pelgrum and Bastiaanssen, 1996; Raupach, 1991; Raupach, 1993; Raupach and Finnigan, 1995; Sellers et al., 1997; Wang et al., 2006). Despite this tremendous effort, the scale issue is still an open question for investigation, and an adequate scaling theory does not yet exist(Beven and Fisher, 1996). 
Depending on the scale of interest and the desired objective, two different strategies for using coarse resolution satellite data in estimating ET over agricultural fields can be mentioned. If the objective is estimating ET at the scale of individual fields, the empirical vegetation index - radiometric surface temperature $\left(\mathrm{NDVI}-\mathrm{T}_{\mathrm{R}}\right)$ relationship can be used for disaggregating $T_{R}$ to the shortwave band resolution. This has been evaluated with moderate success over the Southern Great Plains SGP'97 and SMACEX'02 datasets (Agam et al., 2006; Anderson et al., 2004; Kustas et al., 2003). If the objective is estimating ET over a mixture of different fields, which represents the prime interest of irrigation water planners, procedures which link local to areaaveraged (or effective) surface parameters can be used (Chehbouni et al., 1995; Njoku et al., 1996). In this regard, numerical simulation studies have emphasized the need to develop theoretically-based aggregation schemes, to take into account of the nonlinear nature of the relationships between surface fluxes and surface parameters (Braden, 1995; Lhomme et al., 1994; Raupach and Finnigan, 1995). However, other studies based on experimental field data conclude that simple empirical aggregation rules may provide reasonable estimates of area-averaged surface fluxes (Arain et al., 1996; Blyth and Harding, 1995; Chehbouni et al., 2000; Moran et al., 1997; Noilhan et al., 1997; Sellers et al., 1997).

In addition to the aforementioned spatial issues, remote sensing data together with energy balance models only provide instantaneous values of surface fluxes. These are of limited interest for water managers who are primarily focusing on daily values of ET (Bastiaanssen et al., 2000). Geostationary sensors can provide diurnal courses with temporal sampling from fifteen minutes to 1 hour, but their very coarse spatial resolutions cause additional difficulties. With sun-synchronous sensors, the most common method used for extrapolating instantaneous ET into daily values assumes that the evaporative fraction (EF, defined as the ratio of ET to available energy $\mathrm{AE}$ ) is constant throughout the day. Daily ET can then be derived from instantaneous EF values, provided that measurements or estimates of the AE diurnal cycle are available. The diurnal behavior of EF has been heavily investigated (see (Gentine et al., 2007) for an extended review). However, most - if not all - of these studies have 
been confined to homogeneous situations. The diurnal behavior of EF over heterogeneous surfaces has received little attention.

In this context, the main objective of the current study is to address the spatial and temporal scaling issues, for deriving area-averaged daily values of ET over a patchwork of agricultural fields with different crops and soil moisture conditions. We examine the diurnal behavior of EF and AE over this heterogeneous patchwork, and present a simple approach to derive area-averaged daily ET. This procedure is made up of two components.

- The first component deals with the spatial scaling where a simple aggregation scheme and an energy balance model forced by surface radiometric temperature are combined to derive instantaneous estimates area averaged EF over heterogeneous surfaces.

- The second component deals with the temporal scaling using a heuristic method to scale up instantaneous values to daily ones. It parameterizes the relative diurnal courses of EF and AE from meteorological data, and set their absolute magnitudes from remotely sensed instantaneous fluxes at the satellite overpass time.

To assess the proposed approach, ground based surface temperature as well as atmospheric forcing parameters and surface fluxes were collected in the semi-arid region of the Yaqui Valley, Sonora, north-western Mexico, over 3 adjacent fields which differ in terms of crop types, status and soil moisture conditions.. The paper is organized as follows: section 2 describes the site and the experimental setup, section

3 presents the modeling approach and section 4 presents the results of the comparison between observed and simulated area averaged instantaneous and daily fluxes. Finally, section 5 provides a discussion and concluding remarks.

\section{SITE DESCRIPTION AND EXPERIMENTAL SETUP}

The Yaqui Valley $\left(27^{\circ} \mathrm{N}\right.$ and $\left.110^{\circ} \mathrm{W}\right)$ is the largest agricultural district in the state of Sonora, north-western Mexico, with an area of 220,000 hectares (Figure 1). It is 
bordered on the west by the Gulf of California and on the east by the foothills of the Sierra Madre Occidental. The water for irrigation in the valley is provided by the Alvaro Obregon Reservoir, located on the Yaqui River, which has a capacity of approximately three $\mathrm{km}^{3}$. The climate is very dry: the $2000 \mathrm{~mm}$ annual potential evapotranspiration significantly exceeds the $300 \mathrm{~mm}$ annual rainfall (Schoups et al., 2006). Irrigation represents the largest water consumption (about 90\%) in the valley. An important step towards sound management of the scarce water resources in Northern Mexico is providing accurate estimates of the spatial and temporal variability of water losses to the atmosphere through evapotranspiration.

The experiment took place in 1999 over three fields adjacent to one another of about 100 hectares each of chickpeas, cotton and wheat, during a period from DOY 96 to DOY104). These three fields were representative of the local land use since they corresponded to about $80 \%$ of cropped surfaces within the district. Table 1 displays the average condition of the characteristics of the individual field during the course of the experiment. According to (Shuttleworth, 1988), and considering the field sizes, the surface heterogeneity could be considered as disorganized (micro-scale heterogeneity). This means that the air above the surface is sufficiently mixed so that the atmospheric boundary layer responds to the composite surface structure only. Thus, atmospheric forcing parameters at the blending height can be considered as common to all fields (Mahrt, 2000).

A $10 \mathrm{~m}$ height meteorological tower was equipped with a set of standard meteorological instruments to measure wind speed and direction (R. M. Young, MI, USA), air temperature and humidity (Vaisala, Sweden), and incoming short-wave radiation (Kipp and Zonen, The Netherlands). Net radiation was measured using Q7.1 net radiometers (REBS Inc., WA, USA) over chickpeas and wheat, and a CNR1 net radiometer (Kipp \& Zonen, the Netherlands) over cotton. At each of the three sites, soil heat flux was measured using three HFT3 plates (REBS Inc., WA, USA) buried at a $0.025 \mathrm{~m}$ depth, without accounting for heat storages above the plates. It should mentioned that this heat storage be significant under some conditions, i.e., dry soil and woody vegetation. Soil moisture was measured within each field at 0.05 , 
0.15 and $0.30 \mathrm{~m}$ depths, using three CS600 TDR (Time Domain Reflectometer, Campbell Scientific Inc., UT, USA). Surface temperature was measured over each field using Everest Infra Red Thermometers (IRTs), with view zenith angles of $90^{\circ}$. All IRTs were calibrated against an Everest black body during the experiment, and previously in the laboratory with adjustable ambient temperatures. These meteorological measurements were sampled with a 10 second frequency, and recorded with a 30 minute averaging.

Sensible and latent heat fluxes were measured at a height of $2.9 \mathrm{~m}$ over each site (see Figure 2 for the experimental setup), using 3D sonic anemometers and fast response hygrometers (Campbell Scientific Inc., UT, USA), with sampling frequencies of $10 \mathrm{~Hz}$ (wheat) and $8 \mathrm{~Hz}$ (cotton and chickpeas). The flux data were stored with a 30 minute frequency using 21X (respectively CR10X) data loggers (Campbell Scientific Inc., UT, USA) over the wheat crop (respectively the cotton and chickpea crops). The halfhourly fluxes were later calculated off-line using Eddy Covariance (EC) processing software that performed all required corrections for planar fit correction, humidity and oxygen (KH20). An inter-comparison of the three eddy correlation systems was performed at both the beginning and the end of the experiment. The agreement between the three systems was within the expected range (less than 10\%). However, flux data analysis showed the sum of latent and sensible heat flux measured independently by the EC systems was often lower than AE. This problem could not be explained, either by mismatching spatial extents for fluxes and AE measurements, or by uncertainties associated with measurements of soil heat flux and net radiation (Hoedjes et al., 2002; Twine et al., 2000). Two options for correcting the energy balance non closure were reported in the literature. The first one consists of assuming that closure error lies more heavily in the latent heat component and thus ET measurements should not be used. The other option suggested by (Twine et al., 2000) stipulates that whilst EC underestimates both sensible and latent heat fluxes, their ratio (i.e. the Bowen ratio) is correctly measured. Recent research in micrometeorology indicates that significant flux loss may result from angle-of-attack dependent calibration error in sonic anemometers and from the use of coordinate rotation, which can act as a high-pass filter when applied to short measurement 
periods. Both these effects would apply equally to both fluxes - favoring the second option (Finnigan et al., 2003; Gash and Dolman, 2003; Nakai et al., 2006; van der Molen et al., 2004). In this study however, the second option was somewhat adopted. Thus, sensible and latent heat fluxes were re-computed by forcing the energy balance closure using measured Bowen ratio and AE (Chehbouni et al., 2007b).

\section{MODELLING APPROACH}

\subsection{MODEL FOR SURFACE FLUX ESTIMATES}

\subsubsection{Sensible heat flux}

Regardless of scale, sensible heat flux $H$ is theoretically expressed as the difference between air temperature $T_{a}$ at reference height $z_{r}$ and surface aerodynamic temperature $T_{0}$ obtained by extrapolating the air temperature profile down to the level of the apparent sink for momentum:

$$
H=\rho C p \frac{T_{o}-T_{a}}{r_{a}}
$$

where $\rho$ is air density $\left(\mathrm{kg} \mathrm{m}^{-3}\right), C_{p}$ is air specific heat at constant pressure $\left(J \cdot \mathrm{kg}^{-1} \mathrm{~K}^{-1}\right)$, $T_{a}(\mathrm{~K})$ is air temperature. $T_{0}$ is surface aerodynamic temperature $(\mathrm{K})$ defined at the mean canopy source height. Aerodynamic resistance $r_{a}$ is calculated by means of the classical formulae which take into account the stability correction functions for wind and temperature (Brutsaert, 1982) as:

$$
r_{a}=\frac{1}{k u_{*}}\left[\ln \left(\frac{z_{r}-d}{z_{0}}\right)-\Psi_{h}(\zeta)\right]
$$

with 
$u_{*}=k u_{a} /\left[\ln \left(\frac{z_{r}-d}{z_{0}}\right)-\Psi_{m}(\zeta)\right]$

where $u^{*}$ is friction velocity, $u_{a}$ is wind speed at reference height, $k$ is von Kàrman's constant, $z_{0}$ is roughness length for momentum, $\Psi_{h}$ and $\Psi_{m}$ are the integral diabatic correction functions respectively for heat and momentum given by (Paulson, 1970). $\zeta$ is a dimensionless parameter defined as a function of Monin-Obukhov length $L$, zero plane displacement height $d$, and reference height $z_{r}$ as: $\zeta=\left(z_{r}-d\right) / L$. Both $d$ and $z_{0}$ can be determined following (Choudhury and Monteith, 1988), who fitted simple functions to the curves obtained by (Shaw and Pereira, 1982) from second-order closure theory:

$$
\begin{array}{lc}
d=1.1 h \ln \left(1+X^{1 / 4}\right) & X=c_{d} L A I \\
z_{0}=\left\{\begin{array}{lc}
z_{0 s}+0.3 h X^{1 / 2} & 0<X<0.2 \\
0.3 h(1-d / h) & 0.2<X<1.5
\end{array}\right.
\end{array}
$$

where $c_{d}$ is mean drag coefficient assumed to be uniform within the canopy, LAI is leaf area index (green + dry),$h$ is canopy height. Substrate roughness length $z_{0 s}$ is commonly taken as $0.01 \mathrm{~m}$ for bare soil (Shuttleworth and Wallace, 1985).

Aerodynamic temperature $T_{0}$ can be estimated analytically through the use of a twosource formulation. However, this requires the knowledge of component surface temperatures and resistances for soil and vegetation (Shuttleworth and Wallace, 1985). Component temperatures can be derived by combining multi-directional temperature data and radiative transfer modeling within the thermal infrared (TIR) part of the spectrum (Chehbouni et al., 2001a; Chehbouni et al., 2001b; Merlin and 
Chehbouni, 2004). This is very difficult to implement, especially over heterogeneous surfaces. Indeed, heterogeneities make the interpretation of multi-directional measurements of surface temperature non trivial, while TIR radiative transfer modeling is not yet ready to be implemented operationally in such conditions (Jacob et al., 2007).

For these reasons, aerodynamic temperature is generally replaced by remotely sensed surface radiometric temperature and Equation 1 is adjusted by adding an additional resistance $\left(\mathrm{r}_{\mathrm{ex}}\right)$, to account for the difference between radiometric and aerodynamic temperatures (Lhomme et al., 1997; Stewart et al., 1994) . It reads:

$$
H=\rho c_{p} \frac{T_{R}-T_{a}}{r_{a}+r_{e x}}
$$

The issue of properly taking into account the difference between these two temperatures and thus parameterize $r_{e x}$ has been intensively investigated over the past two decades (Blumel, 1999; Brutsaert and Sugita, 1996; Cahill et al., 1997; Chehbouni et al., 1996; Crago, 1998; Hall et al., 1992; Kubota and Sugita, 1994; Kustas, 1990; Kustas et al., 1989; Lhomme et al., 1994; Lhomme et al., 1997; Malhi, 1996; Massman, 1999; Mathias et al., 1987; Norman and Becker, 1995; Stewart et al., 1994; Su, 2002; Sugita and Brutsaert, 1996; Sugita and Kubota, 1994; Sun and Mahrt, 1995; Troufleau et al., 1997; Verhoef et al., 1997; Watts et al., 2000).

The extra resistance, which aims at linking surface aerodynamic and radiometric temperatures, depends on various factors which drive both temperatures. Aerodynamic temperature is driven by canopy structure, meteorological conditions and vegetation water status. Remotely sensed radiometric temperature is driven by the same surface properties, but also depends on illumination and viewing conditions, as well as by the instrument IFOV.

In this study, we adopted an expression for the extra resistance developed by (Lhomme et al., 2000) through a comprehensive study based on physically based 
SVAT modeling. This expression seemed to perform correctly over a wide range of surface conditions and view angles. This resistance was expressed in terms of friction velocity $\mathbf{u}$ * and Leaf Area Index LAI for a nadir looking TIR radiometer as:

$r_{e x}=\left[\sum_{n=0}^{n=6} a_{n} L A I^{n}\right] u_{*}^{-1}$

using the polynomial coefficients $a_{n}$ given by (Lhomme et al., 2000).

\subsubsection{Net radiation}

Net radiation $R_{n}$ provides the available radiative energy to be allocated between crop evapotranspiration, photosynthesis, and soil and atmospheric heating (Monteith and Unsworth, 1990). In the current study, the net radiation was expressed as:

$$
R_{n}=(1-\alpha) R_{g}+\varepsilon_{S} R_{a}-R_{t}
$$

where $a$ is surface albedo, $R_{g}$ is global solar radiation $\left[\mathrm{W} \mathrm{m} \mathrm{m}^{-2}\right], \varepsilon_{s}$ is surface emissivity,

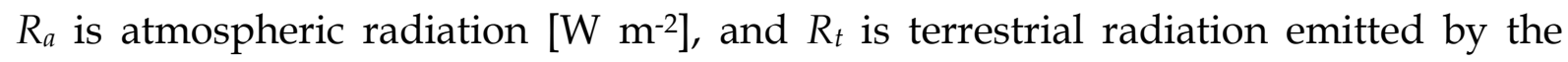
surface $\left[\mathrm{W} \mathrm{m}^{-2}\right]$. By using the Stefan-Boltzman equation (Monteith and Unsworth, 1990), $R_{a}$ and $R_{t}$ could be expressed as functions of temperature and emissivity of air and surface. Then, Eq. (8) could be rewritten as:

$$
R_{n}=(1-\alpha) R_{g}+\varepsilon_{S} \sigma\left(\varepsilon_{a} T_{a}^{4}-T_{R}^{4}\right)
$$

Where $\varepsilon_{a}$ is atmosphere emissivity, and $\sigma$ is Stefan-Boltzmann constant $\left(5.67 \times 10^{-8} \mathrm{~W}\right.$ $\mathrm{m}^{-2} \mathrm{~K}^{-4}$ ). In the current study, we used the expression proposed by (Brutsaert, 1982) where $\varepsilon_{a}$ is computed from air temperature and vapor pressure as:

$$
\varepsilon_{a}=1.24\left(e_{a} / T_{a}\right)^{1 / 7}
$$


where $e_{a}$ is air vapor pressure $(\mathrm{hPa})$.

\subsubsection{Soil heat flux}

Due to the complexities of land surface cover and soil physical processes, soil heat flux $G$ is the most difficult scalar to measure accurately at the appropriate spacescale. Several authors have related this scalar to the net radiation (Stull, 1988; Villalobos et al., 2000). The most common approach is to parameterize $G$ as a constant proportion of $R_{n}$, fixed to a given value throughout the day. Recommended values for the ration $G / R_{n}$ in the literature range from 0.15 to 0.40 (Brutsaert, 1982; Humes et al., 1994; Kustas and Goodrich, 1994), with typical values around 0.30 for sparse canopies. As reported in (Santanello and Friedl, 2003), G is unfortunately neither constant nor negligible on diurnal time scales. G/Rn can range from 0.05 to 0.50 and is driven by several factors: time of day, soil moisture and thermal properties, as well as vegetation amount and height (Kustas et al., 1993). In this study, we used the simple formula proposed by (Santanello and Friedl, 2003), which allows soil heat flux to be derived from remotely sensed net radiation:

$G / R_{n}=A \cos [2 \pi(t+10800) / B]$

where $t$ is time of day in seconds, and A and B are adjusting factors which were set by (Santanello and Friedl, 2003), of 0.31 and 74000 s, respectively. This relationship was chosen in this study because it has been proven to provide improvement to modeled values of $G$ relative to other currently available methods.

Providing that sensible heat flux $H$, net radiation $R_{n}$ and soil heat flux $G$ are obtained using the aforementioned formulations, latent heat flux $L E$ can be derived as the residual term of the energy balance equation.

\subsection{AGGREGATION PROCEDURE}


Theoretically-based aggregation schemes for surface fluxes are certainly exact and elegant. However, a major drawback of these schemes is they cannot be routinely applied to models which operate at grid scale in a free running predictive mode (Shuttleworth et al., 1997). Consequently, the simple aggregation procedure used in this study is based on two assumptions. The first one consists of formulating gridscale surface fluxes using the same equations that govern patch-scale behavior but whose arguments are the aggregate expressions of those at the patch-scale. The second one stipulates "the effective or area-averaged value of land surface parameters is estimated as a weighted average over the component cover types in each grid through that function involving the parameter which most succinctly expresses its relationship with the associated surface flux" (Shuttleworth et al., 1997). Applying this simple aggregation rule to area-averaged (denoted by angle brackets) net radiation, sensible heat flux, soil heat flux, and evaporative fraction leads to:

$$
\begin{aligned}
& \left\langle R_{n}\right\rangle=(1-\langle\alpha\rangle) R_{g}+\left\langle\varepsilon_{S}\right\rangle \sigma\left(\varepsilon_{a} T_{a}^{4}-\left\langle T_{R}^{4}\right\rangle\right) \\
& \langle H\rangle=\rho c p \frac{\left\langle T_{R}\right\rangle-T_{a}}{\left\langle r_{a}\right\rangle+\left\langle r_{e x}\right\rangle}
\end{aligned}
$$

$$
\begin{aligned}
& \frac{\langle G\rangle}{\left\langle R_{n}\right\rangle}=A \cos [2 \pi(t+10800) / B] \\
& \langle E F\rangle=\frac{\left\langle L_{v} E\right\rangle}{\left\langle R_{n}\right\rangle-\langle G\rangle}=\frac{\left\langle R_{n}\right\rangle-\langle G\rangle-\langle H\rangle}{\left\langle R_{n}\right\rangle-\langle G\rangle}
\end{aligned}
$$


Similarly, the application of the second assumption leads to the following set of relationships between local (subscript i) and effective (in brackets) radiative temperature, surface emissivity, surface albedo, the displacement height, leaf area index, and roughness length:

$$
\left\langle T_{R}\right\rangle=\frac{\left[\sum_{i=1}^{3} f_{i} \varepsilon_{i}\left(T_{R_{i}}\right)^{4}\right]^{0.25}}{\langle\varepsilon\rangle}
$$

$\langle\varepsilon\rangle=\sum_{i=1}^{3} f_{i} \varepsilon_{i}$

$$
\langle\alpha\rangle=\sum_{i=1}^{3} f_{i} \alpha_{i}
$$

$$
\langle d\rangle=\sum_{i=1}^{3} f_{i} d_{i}
$$

$$
\langle L A I\rangle=\sum_{i=1}^{3} f_{i} L A I_{i}
$$

$$
\ln ^{-2}\left[\frac{z_{b}-\langle d\rangle}{\left\langle z_{o}\right\rangle}\right]=\sum_{i=1}^{3} f_{i} \ln ^{-2}\left(\frac{z_{b}-d_{i}}{z_{o i}}\right)
$$

where $f_{i}$ is the fraction covered by the biome/patch $\mathrm{i}$, and $\mathrm{z}_{\mathrm{b}}$ is the so-called blending height defined as a level in the atmosphere where turbulent mixing is sufficient so that it can be assumed that the atmosphere has become adapted to the different types of land cover on the ground below (Wieringa, 1986). The blending height was 
estimated to of the order $l / 100$, where $l$ is the characteristic horizontal scale of the different patches making up the grid (roughly about $1 \mathrm{~km}$ in the present study) which leads to a value of $\mathrm{z}_{\mathrm{b}}$ of about $10 \mathrm{~m}$, corresponding to about the height where the atmospheric forcing parameters were measured.

\subsection{PARAMETERIZATION OF THE DIURNAL BEHAVIOR OF EF AND AE OVER} HETEROGENEOUS SURFACES

The diurnal behavior of EF depends on both atmospheric loading and surface conditions. On the one hand, evaporative demand is controlled by incoming radiation, relative humidity and, to a lesser extent, wind speed. On the other hand, surface control is exerted by soil moisture and vegetation condition. This issue has been heavily investigated from both experimental and theoretical perspectives, but mainly over a single vegetation type (Crago and Brutsaert, 1996; Crago, 1996; Lhomme and Elguero, 1999; Lu and Lemeur, 1995). Most of these studies have reported a typical concave-up shape for EF. Such typical shape can induce errors when assuming a daytime constant EF equal to the noon value, since the latter is always lower than the daily average (Gentine et al., 2007). It was thus of interest to examine this issue over a heterogeneous surface which included different land use and soil moisture conditions.

In Figure 3, we present measured daily course of EF over cotton, chickpeas and wheat field respectively along with their area averaged during the study period. Two conclusions can be drawn from this figure. First, the magnitude of EF varies from site to site, which confirms the contrast in terms of soil moisture status among the three sites. Second, the assumption of the self conservation of EF during day time hours is only valid under dry conditions (chickpea field), while a pronounced diurnal cycle is seen under wet conditions (wheat and cotton fields). Therefore, the generalization of 
this self preservation assumption to all surface conditions may induce important errors in estimating latent heat fluxes.

In the current study, the method developed by (Hoedjes et al., 2007) over a homogeneous surface is generalized to the mixture of three fields. The parameterization of the EF diurnal behavior was formulated as a function of the main atmospheric forcing parameters, i.e. incoming solar radiation $\mathrm{R}_{\mathrm{g}}\left(\mathrm{W} \mathrm{m}^{-2}\right)$ and relative humidity $\mathrm{RH}(\%)$ which characterize the EF daily shape. The magnitude of day to day EF is controlled by soil moisture status. It was characterized here by the EF instantaneous value at $1400\left(\mathrm{EF}^{1400}\right)$, which can be obtained from sun synchronous satellite data. In this study, the time of $14 \mathrm{~h} 00$ was chosen since it corresponds to the local time of overpass of the AVHRR satellite. (Hoedjes et al., 2007) showed this parameterization was also pertinent when choosing the ASTER overpass time over Morocco, i.e. 11h30. Though further analysis is required to confirm this, it is expected that the use of satellite overpass between $09 \mathrm{~h} 00$ and $16 \mathrm{~h} 00$ should be adequate, since these correspond to optimal times for computing land surface fluxes. Finally, the proposed formulation takes advantage of assuming EF self-preservation to be valid under dry conditions. Thus, a threshold depending on the Bowen ratio (H/LE) at $14 \mathrm{~h} 00$, labeled $\beta^{1400}$, is used to switch from a constant to a daily variable EF.

$$
\begin{aligned}
& \left\langle E F_{\operatorname{Sim}}^{A C T}\right\rangle=\left\{\begin{array}{cc}
\left\langle E F_{\text {Sim }}\right\rangle r_{E F}^{1400} & \left\langle\beta^{1400}\right\rangle \leq 1.5 \\
\left\langle E F_{\operatorname{Re} m}^{1400}\right\rangle & \text { pour }
\end{array}\right. \\
& \left\langle E F_{\text {Sim }}\right\rangle=A-\left(B \frac{R_{g}}{1000}+C \frac{R H}{100}\right) \\
& r_{E F}^{1400}=\frac{\left\langle E F_{\operatorname{Re} m}^{1400}\right\rangle}{\left\langle E F_{\operatorname{Sim}}^{1400}\right\rangle}
\end{aligned}
$$


Where $\left\langle E F_{\text {Sim }}\right\rangle$ is the EF diurnal course parameterized when accounting for atmospheric demand only, $\left\langle E F_{\text {Sim }}^{A C T}\right\rangle$ is the (actual) EF diurnal course parameterized when accounting for both atmospheric demand and soil moisture status, $\left\langle E F_{\operatorname{Sim}}^{1400}\right\rangle$ is $\left\langle E F_{\operatorname{Sim}}\right\rangle$ at $14 \mathrm{~h} 00$, and $\left\langle E F_{\operatorname{Re} m}^{1400}\right\rangle$ is the EF estimated from remote sensing observations at $14 \mathrm{~h} 00$. A, B and C are calibration parameters which were derived by (Hoedjes et al., 2007) over a homogeneous olive orchard in Morocco $\left(\mathrm{A}=1.2, \mathrm{~B}=0.4 \mathrm{~W}^{-1} \cdot \mathrm{m}^{2}\right.$, and $\left.\mathrm{C}=0.5\right)$.

Once the diurnal course of EF could be derived from meteorological and remote sensing observations, recovering the daily ET values also required AE over the diurnal cycle. Given the possibility of estimating the instantaneous AE from sun synchronous satellite images at the time of overpass, it was of interest to combine such remote sensing observations with a simple parameterization to derive the $\mathrm{AE}$ diurnal cycle. Here again, the same heuristic approach developed in (Hoedjes et al., 2007) for homogeneous conditions was generalized to heterogeneous conditions. The daily variation of area-averaged $\mathrm{AE}$ was formulated by combining the AE estimated from remote sensing at $14 \mathrm{~h} 00\left\langle A E_{\operatorname{Re} m}^{1400}\right\rangle$ with a function $<\mathrm{R}>$ involving meteorological information which can obtained from observation networks and/or weather forecasts (Er-Raki et al., 2007):

$$
\left(\frac{(\langle A E\rangle)^{t}}{(\langle A E\rangle)_{\operatorname{Re} m}^{1400}}\right)=f\left(\frac{\left\langle R^{t}\right\rangle}{\left\langle R^{1400}\right\rangle}\right)
$$

with

$$
\left\langle R^{t}\right\rangle=(1-\langle\alpha\rangle) R_{g}^{t}+\langle\varepsilon\rangle \varepsilon_{a}^{t}\left(T_{a}^{t}\right)^{4}
$$




$$
f\left(\frac{\left\langle R^{t}\right\rangle}{\left\langle R^{1400}\right\rangle}\right)=\sum_{\substack{n=0 \\ n=0}}^{n=3}\left[\frac{\left\langle R^{t}\right\rangle}{\left\langle R^{1400}\right\rangle}\right]^{n}
$$

where $t$ is time of the day. This function was used with the following polynomial coefficients $b_{2}=0.34 ; b_{1}=1.15 ; b_{0}=-0.48$, which were obtained by (Hoedjes et al., 2007) when calibrating over a homogeneous olive orchard in Morocco.

\section{Results}

The performance of the proposed approach was assessed by considering the daytime data collected during the study period. Indeed, the latter provided an ideal situation since it corresponded to a substantial variability between the three fields in terms of energy partitioning. As shown in Figure 3, the chickpea field was very dry during the whole period, the wheat field was in drying stage after an irrigation event on DOY 90, and the cotton field was dry initially and then again after an irrigation event on DOY 96. Figure 3 especially shows the shape of EF was almost constant for the chickpea site under dry conditions, while it exhibited a distinct concave shape under wet condition for both the wheat field and the cotton field once irrigated. This confirmed the findings of (Hoedjes et al., 2007) over an olive orchard in Morocco, under climatic conditions (precipitation $240 \mathrm{~mm}$ / evaporative demand $1700 \mathrm{~mm}$ ) which were comparable to those of the Yaqui Valley (300 mm / $2000 \mathrm{~mm}$ ).

Figure 4 displays a comparison between sensible heat flux at 14 h00 derived from the proposed method (simulated $\mathrm{H}$ ) against ground based measurements (measured $\mathrm{H}$ ). Simulated $\mathrm{H}$ corresponded to area-averaged values obtained from Eq. 13, by combining Eq. 16, and 17 for radiometric temperature, and Eq. 2, 19, 20 and 21 for aerodynamic resistance. Measured $\mathrm{H}$ was obtained by area-averaging sensible heat fluxes measured over the individual fields. The correspondence between observations and simulations for area-averaged fluxes was very good: the RMSE value was about $12 \mathrm{Wm}^{-2}$, and the linear regression forced to the origin yielded a 1.01 slope value and a 0.98 correlation coefficient. Similarly to sensible heat flux at $14 \mathrm{~h} 00$ 
with Figure 4, the same comparisons are displayed for available energy (AE) and latent heat flux (LE) with Figures 5 and 6, respectively. The correspondences between measured and simulated fluxes were very good: for available energy and latent heat flux, we obtained $\mathrm{R}^{2}$ values of 1 and 0.93 , RMSE values of 3 and $12 \mathrm{~W} \mathrm{~m}^{2}$, and mean biases of 3 and $0.96 \mathrm{~W} \mathrm{~m}^{-2}$, respectively. However the $\mathrm{R}^{2}$ of $\sim 1$ between observations and simulations of area-averaged available energy was "remarkably" good. The explanation could be twofold. Firstly, compensation effects may occur between net radiation and soil heat flux. Secondly, available energy was mainly controlled by the incoming solar radiation, which was measured in-situ and used as input for both simulations and observations. Overall, these results showed that, at least under the prevailing conditions within the considered study site, the proposed approach provided accurate estimates of area average instantaneous surface fluxes, over heterogeneous surfaces including different land use and soil moisture conditions. However, such excellent results probably represent a "best case scenario", since they were obtained using ground based measurements which did not include actual intra field heterogeneities which are more likely to occur especially with flood irrigation.

Once area-averaged values of instantaneous evaporative fraction at $14 \mathrm{~h} 00$ had been derived, they were used along with Eq. 22 to retrieve the diurnal course of areaaveraged EF. The comparison of these retrievals against ground based measurements is shown in Fig. 7, with ground references of diurnal courses obtained by aggregating EF measurements from the eddy covariance system. Although good agreement was observed for EF values lower than 0.8, otherwise simulations underestimated observations. However, these underestimations were expected to have minor impacts, since they corresponded to low values of AE and LE. Indeed, they occurred for large EF values during early morning and late afternoon parts of the concave-up diurnal course. Finally we note that the coefficients in Eq. 23 could certainly be adjusted to fit the measured diurnal course of EF. However, such tuning is not really worth, as will be shown in the next section.

The final step before obtaining the diurnal course of area-averaged ET was retrieving that of area-averaged available energy (AE) from Eq. 25. The comparison of AE 
retrievals against ground based measurements is shown in Fig. 8. Linear regression forced through the origin yielded a slope of 0.96 and a correlation coefficient of 0.97 , while RMSE and bias values were 28 and $-7.85 \mathrm{~W} \mathrm{~m}^{-2}$, respectively. These results were comparable to those reported by (Hoedjes et al., 2007), indicating the parameterization scheme could be applied over the heterogeneous area considered, under the current environmental and experimental contexts. Figure 9 displays a comparison between simulations and observations for the diurnal course of areaaveraged $L E$, when using measured available energy instead of parameterization (i.e only EF parameterization is considered). Also included is the area-averaged $L E$, calculated by considering a constant diurnal EF equal to that at $14 \mathrm{~h} 00$ (EF14h00). It is shown the actual diurnal course of $L E$ was better approximated when using the simulated $\mathrm{EF}$ rather than a constant value equal to $\mathrm{EF}_{14 \mathrm{~h} 00}$. Indeed, the latter induced overestimation of large LE values around solar noon and underestimation low LE values during early morning and late afternoon. The resulting improvement in terms of accuracy on the retrieved LE diurnal course was the following: RMSE of $12 \mathrm{~W} \mathrm{~m}^{-2}$ instead of $22 \mathrm{~W} \mathrm{~m}^{-2}$, bias of $-5 \mathrm{~W} \mathrm{~m}^{-2}$ instead of $2 \mathrm{~W} \mathrm{~m}^{-2}$, and correlation coefficient of 0.98 instead of 0.94 .

Finally, the diurnal course of area-averaged LE was calculated by combining the parameterizations of both $\mathrm{AE}$ and EF. Fig. 10 shows the validation of these LE retrievals, against ground truth derived from eddy covariance data through areaaveraging. Linear regression forced to the origin yielded a 0.93 slope, a 0.93 correlation coefficient, while RMSE and bias values were 20 and $-9 \mathrm{~W} \mathrm{~m}^{-2}$, respectively. The obtained results were considered as very good, given the following features for the retrieved diurnal courses of area-averaged LE: they were representative of an heterogeneous area, they depended on few instantaneous measurements (surface and air temperature, wind speed) and few diurnal observations (incoming radiation and relative humidity). This implied the two tested parameterizations, either separately or combined, can be useful for large scale irrigation water management on an operational basis. However, the proposed approach was applied using data collected locally at the surface. The next stage is implementation over observations at larger scale, including actual remote sensing 
data, and ground based EC or scintillometer systems embracing different land surface patches. This will raise new questions in terms of applicability and performances, as discussed in the next section.

\section{SUMMARY AND CONCLUSIONS}

For sustainable irrigation water management in arid and semi-arid regions, accurate knowledge of evapotranspiration is of paramount importance to optimize crop water supply. Over the last two decades, several approaches have been developed to incorporate remotely sensed data into evapotranspiration models, so that water consumption can be estimated in a spatially distributed manner. However, remotely sensed observations are usually collected from sun-synchronous sensors, making such instantaneous information at satellite overpass of little use for water management. In order to obtain daily estimates of evapotranspiration, a constant evaporative fraction (EF) is usually assumed, to be used together with measurements or simulations of available energy. However, EF can display a distinct concave-up shape during daytime, especially under wet conditions. This means that the use of a constant EF value produces significant errors in terms of deriving the diurnal course of latent heat flux (Hoedjes et al. 2007). A practical alternative is then obtaining heuristic parameterization for the diurnal course of $\mathrm{EF}$, and extending it to that of available energy, where the formulations considered make use of meteorological information that is potentially available from observation networks and/or weather forecasts. Such an approach was validated by (Hoedjes et al., 2007) over a relatively homogeneous olive orchard. The current study aimed at assessing this approach (without any adjustment) over a heterogeneous area which included different fields in terms on land use and soil moisture conditions.

Extending the proposed approach to heterogeneous conditions was performed using aggregation schemes proposed by (Chehbouni et al., 2007b; Chehbouni et al., 2000; Ezzahar et al., 2007). Especially, the retrieval of instantaneous evaporative fraction relied on a simple aggregation scheme and surface radiometric temperature, to derive instantaneous estimates of the energy balance components. This aggregation 
scheme can potentially retrieve fluxes from TIR remote sensing data at coarser spatial resolution, by using higher resolution solar remote sensing data. The proposed method was validated using ground based measurements of energy balance components, obtained by area-averaging surface fluxes measured over individual fields. This validation exercise provided very promising results, thanks to the effective procedures proposed for both spatial and temporal upscaling. This indicates the proposed method may be used for estimating evapotranspiration over heterogeneous irrigated areas in semiarid regions, given that no adjustment was performed when transferring the methodology from the environmental conditions of Central Morocco to those of the Yaqui Valley. Another interest is retrieving diurnal surface fluxes, as valuable information to be assimilated into hydrological models, for improving the performances of these models.

Finally, it is worth noting that these very promising initial results have to be confirmed by implementing the proposed approach using datasets which include airborne and/or space-borne remotely sensed observations and ground based measurements of surface fluxes collected for heterogeneous conditions. Indeed, to provide the much needed information about water use and consumption at the irrigation district scale, it is necessary using remote sensing data and meteorological information from observation networks and/or weather forecasts. Then additional questions rise in terms of applicability and accuracy: performances of atmospheric corrections, uncertainties on retrievals of land surface variables (albedo, temperature, LAI, roughness length...), influence of directional effects and sub pixel heterogeneities, relevance of meteorological information from observation networks and/or weather forecasts. A forthcoming field experiment over the same irrigated zone will allow us to address these questions, about the operational use of the approach proposed in the current study.

\section{ACKNOWLEDGEMENTS}


This study has been funded by CONACyT Project 29340T, the French PNTS and TOSCA. Additional funding was provided by the E.U. through PLEIADeS (GOCE 037095) projects.

\section{References}

Agam, N., Kustas, W.P., Anderson, M.C., Li, F. and Neale, C.M.U., 2006. A vegetation index based technique for spatial sharpening of thermal imagery. Remote Sensing of Environement. In press.

Aman, A., Randriamanantena, H.P., Podiare, A. and Froutin, R., 1992. Upscaling integration of normalized difference vegetation index : the problem of spatial heterogeneity. IEEE Transaction on Geoscience and Remote Sensing. 30, 326338.

Anderson, M.C. et al., 2004. A multiscale remote sensing model for disaggregating regional fluxes to micrometeorological scales. Journal of Hydrometeorology. 5 (2), 343-363.

Arain, A.M., Michaud, J. and Shuttleworth, W.J., 1996. Testing of vegetation parameter aggregation rules applicable to the biosphere-atmosphere transfer scheme (BATS) and the FIFE site. Journal of Hydrology. 177 (1-2), 1-22.

Avissar, R., 1998. Which type of soil-vegetation-atmosphere transfer scheme is needed for general circulation models: a proposal for a higher-order scheme. Journal of Hydrology. 213 (1-4), 136-154.

Bastiaanssen, W.G.M., Molden, D.J. and Makin, I.W., 2000. Remote sensing for irrigated agriculture: examples from research and possible applications. Agricultural Water Management. 46 (2), 137-155.

Betts, A.K., Chen, F., Mitchell, K.E. and Janjic, Z.I., 1997. Assessment of the land surface and boundary layer models in two operational versions of the NCEP Eta Model using FIFE data. Monthly Weather Review. 125 (11), 2896-2916.

Beven, K.J. and Fisher, J., 1996. Remote sensing and scaling in hydrology. In J. B. Stewart, E. T. Engman, R. A. Feddes, \& Y.H. Kerr (Eds.), Scaling up in hydrology using remote sensing. Chichester, UK: John Wiley \& Sons.

Blumel, K., 1999. A simple formula for estimation of the roughness length for heat transfer over partly vegetated surfaces. Journal of Applied Meteorology. 38 (6), 814-829.

Blyth, E.M. and Harding, R.J., 1995. Application of Aggregation Models to Surface Heat-Flux from the Sahelian Tiger Bush. Agricultural and Forest Meteorology. 72 (3-4), 213-235.

Braden, H., 1995. Energy Fluxes from Heterogeneous Terrain - Averaging Input Parameters of the Penman-Monteith Formula. Agricultural and Forest Meteorology. 75 (1-3), 121-133.

Brutsaert, W., 1982. Evaporation into the Atmosphere. Reidel, Dordrecht, 299 pp.

Brutsaert, W. and Sugita, M., 1996. Sensible heat transfer parameterization for surfaces with anisothermal dense vegetation. Journal of the Atmospheric Sciences. 53 (2), 209-216. 
Cahill, A.T., Parlange, M.B. and Albertson, J.D., 1997. On the Brutsaert temperature roughness length model for sensible heat flux estimation. Water Resources Research. 33 (10), 2315-2324.

Chehbouni, A. et al., 2007a. The Use of Remotely Sensed data for Integrated Hydrological Modeling in Arid and Semi-Arid Regions: the SUDMED Program. International Journal of Remote Sensing. Accepted.

Chehbouni, A., Ezzahar, J., Watts, C., Rodriguez, J.C. and Garatuza-Payan, J., 2007b. Estimating area-averaged surface fluxes over contrasted agricultural patchwork in a semi-arid region. In J. Hill, A. Röder (Eds.), Advances in Remote Sensing and Geoinformation Processing for Land Degradation Assessment, Taylor and Francis, In Press.

Chehbouni, A. et al., 2000. A preliminary synthesis of major scientific results during the SALSA program. Agricultural and Forest Meteorology. 105 (1-3), 311-323.

Chehbouni, A., Lo Seen, D., Njoku, E.G. and Monteny, B.A., 1996. A Coupled Hydrological and Ecological modeling Approach to examine the Relationship between Radiative and Aerodynamic Surface Temperature over Sparsely Vegetated Surfaces. Remote Sensing of Environement. 58, 177-186.

Chehbouni, A., Njoku, E.G., Lhomme, J.P. and Kerr, Y.H., 1995. Approaches for Averaging Surface Parameters and Fluxes over Heterogeneous Terrain. Journal of Climate. 8 (5), 1386-1393.

Chehbouni, A. et al., 2001a. Directional effect on radiative surface temperature measurements over a semiarid grassland site. Remote Sensing of Environment. 76 (3), 360-372.

Chehbouni, A. et al., 2001b. Estimation of surface sensible heat flux using dual angle observations of radiative surface temperature. Agricultural and Forest Meteorology. 108 (1), 55-65.

Choudhury, B.J. and Monteith, J.L., 1988. A four-layer model for the heat budget of homogeneous land surfaces. Quart. J. Roy. Meteorol. Soc. 114, 373-398.

Courault, D., Seguin, B. and Olioso, A., 2005. Review on estimation of evapotranspiration from remote sensing data: From empirical to numerical modeling approaches. Irrigation and Drainage Systems. 19, 223-249.

Crago, R. and Brutsaert, W., 1996. Daytime evaporation and the self-preservation of the evaporative fraction and the Bowen ratio. Journal of Hydrology. 178 (1-4), 241-255.

Crago, R.D., 1996. Conservation and variability of the evaporative fraction during the daytime. Journal of Hydrology. 180 (1-4), 173-194.

Crago, R.D., 1998. Radiometric and Equivalent Isothermal Surface Temperatures. Water Resources Research. 34, 3017-3023.

Er-Raki, S. et al., 2007. Assessment of reference evapotranspiration methods in semiarid regions: Can weather forecast data be used as alternate of ground meteorological parameters? Irrigation and Drainage Systems.Submitted.

Ezzahar, J., Chehbouni, A., Hoedjes, J.C.B. and Chehbouni, A., 2007. On the application of scintillometry over heterogeneous grids. Journal of Hydrology. 334 (3-4), 493-501.

Finnigan, J.J., Clement, R., Malhi, Y., Leuning, R. and Cleugh, H.A., 2003. A reevaluation of long-term flux measurement techniques - Part I: Averaging and coordinate rotation. Boundary-Layer Meteorology. 107 (1), 1-48. 
Gash, J.H.C. and Dolman, A.J., 2003. Sonic anemometer (co)sine response and flux measurement I. The potential for (co)sine error to affect sonic anemometerbased flux measurements. Agricultural and Forest Meteorology. 119 (3-4), 195207.

Gentine, P., Entekhabi, D., Chehbouni, A., Boulet, G. and Duchemin, B., 2007. Analysis of evaporative fraction diurnal behaviour. Agricultural and Forest Meteorology. 143 (1-2), 13-29.

Hall, F.G., Huemmrich, K.F., Goetz, S.J., Sellers, P.J. and Nickeson, J.E., 1992. Satellite Remote-Sensing of Surface-Energy Balance - Success, Failures, and Unresolved Issues in Fife. Journal of Geophysical Research-Atmospheres. 97 (D17), 1906119089.

Hipps, L.E. and Kustas, W.P., 2000. Surface evaporation and its spatial variations. In R. B. Grayson, G. Blöschl (Eds.), Spatial patterns in catchment hydrology. Cambridge, UK: Cambridge University Press.

Hoedjes, J.C.B., Chehbouni, A., Jacob, F., Ezzahar, J. and Boulet, G., 2007. Can instantaneous evaporative fraction, estimated from remote sensing, be used to derive day-time evapotranspiration over irrigated olive orchards in semiarid regions? Journal of Hydrology . Submitted.

Hoedjes, J.C.B., Zuurbier, R.M. and Watts, C.J., 2002. Large aperture scintillometer used over a homogeneous irrigated area, partly affected by regional advection. Boundary-Layer Meteorology. 105 (1), 99-117.

Humes, K.S., Kustas, W.P., Moran, M.S., Nichols, W.D. and Weltz, M.A., 1994. Variability of Emissivity and Surface-Temperature over a Sparsely Vegetated Surface. Water Resources Research. 30 (5), 1299-1310.

Jacob, F. et al., 2007. Modeling and inversion in thermal infrared remote sensing over vegetated land surfaces. In S. Liang (Ed.), Advances in Land Remote Sensing: System, Modelling, Inversion and Application. Springer, In Press.

Kubota, A. and Sugita, M., 1994. Radiometrically Determined Skin Temperature and Scalar Roughness to Estimate Surface Heat-Flux .1. Parameterization of Radiometric Scalar Roughness. Boundary-Layer Meteorology. 69 (4), 397-416.

Kustas, W.P., 1990. Estimates of evapotranspiration with a one- and two-layer model of heat transfer over partial canopy cover. Journal of Applied Meteorology. 29, 704-715.

Kustas, W.P. et al., 1989. Determination of sensible heat flux over sparse canopy using thermal infrared data. Agricultural and Forest Meteorology. 44, 197-216.

Kustas, W.P. and Goodrich, D.C., 1994. Special Section - Monsoon 90 Multidisciplinary Experiment - Preface. Water Resources Research. 30 (5), 1211-1225.

Kustas, W.P. and Norman, J.M., 1997. A two-source approach for estimating turbulent fluxes using multiple angle thermal infrared observations. Water Resources Research. 33 (6), 1495-1508.

Kustas, W.P., Norman, J.M., Anderson, M.C. and French, A.N., 2003. Estimating subpixel surface temperatures and energy fluxes from the vegetation indexradiometric temperature relationship. Remote Sensing of Environment. 85 (4), 429-440.

Kustas, W.P., Norman, J.M., Schmugge, T.J. and Anderson, M.C., 2004. Mapping Surface Energy Fluxes with Radiometric Temperature. In D. Quattrochi and J. 
Luvall (eds.), Thermal Remote Sensing in Land Surface Processes, Taylor and Francis, New York. 205-253.

Kustas, W.P. et al., 1993. Relationships between Evaporative Fraction and RemotelySensed Vegetation Index and Microwave Brightness Temperature for Semiarid Rangelands. Journal of Applied Meteorology. 32 (12), 1781-1790.

Lhomme, J.P., 1992. Energy-Balance of Heterogeneous Terrain - Averaging the Controlling Parameters. Agricultural and Forest Meteorology. 61 (1-2), 11-21.

Lhomme, J.P., Chehbouni, A. and Monteny, B., 1994. Effective Parameters of SurfaceEnergy Balance in Heterogeneous Landscape. Boundary-Layer Meteorology. 71 (3), 297-309.

Lhomme, J.P., Chehbouni, A. and Monteny, B., 2000. Sensible heat flux-radiometric surface temperature relationship over sparse vegetation: Parameterizing B-1. Boundary-Layer Meteorology. 97 (3), 431-457.

Lhomme, J.P. and Elguero, E., 1999. Examination of evaporative fraction diurnal behaviour using a soil-vegetation model coupled with a mixed-layer model. Hydrology and Earth System Sciences. 3 (2), 259-270.

Lhomme, J.P., Troufleau, D., Monteny, B., Chehbouni, A. and Bauduin, S., 1997. Sensible heat flux and radiometric surface temperature over sparse Sahelian vegetation .2. Model for the kB(-1) parameter. Journal of Hydrology. 189 (1-4), 839-854.

Lu, Z. and Lemeur, R., 1995. Evaluation of Daily Evapotranspiration Estimates from Instantaneous Measurements. Agricultural and Forest Meteorology. 74 (1-2), 139-154.

Mahrt, L., 2000. Surface heterogeneity and vertical structure of the boundary layer. Boundary-Layer Meteorology. 96 (1-2), 33-62.

Malhi, Y., 1996. The behaviour of the roughness length for temperature over heterogeneous surfaces. Quarterly Journal of the Royal Meteorological Society. 122 (533), 1095-1125.

Massman, W.J., 1999. A model study of $\mathrm{kB}(\mathrm{H})(-1)$ for vegetated surfaces using 'localized near-field' Lagrangian theory. Journal of Hydrology. 223 (1-2), 27-43.

Mathias, A.D., Yates, S.R., Zhang, R. and Warrick, A.W., 1987. Radiant temperatures of sparse plant canopies and soil using IR thermometry. IEEE Transaction on Geoscience and Remote Sensing. 25, 516-519.

McCabe, M.F. and Wood, E.F., 2006. Scale influences on the remote estimation of evapotranspiration using multiple satellite sensors. Remote Sensing of Environment. 105 (4), 271-285.

McNaughton, K.G., 1994. Effective Stomatal and Boundary-Layer Resistances of Heterogeneous Surfaces. Plant Cell and Environment. 17 (9), 1061-1068.

Merlin, O. and Chehbouni, A., 2004. Different approaches in estimating heat flux using dual angle observations of radiative surface temperature. International Journal of Remote Sensing. 25 (1), 275-289.

Merlin, O., Chehbouni, A., Kerr, Y.H. and Goodrich, D.C., 2006. A downscaling method for distributing surface soil moisture within a microwave pixel: Application to the Monsoon '90 data. Remote Sensing of Environment. 101 (3), 379-389.

Merlin, O., Chehbouni, A.G., Kerr, Y.H., Njoku, E.G. and Entekhabi, D., 2005. A combined modeling and multipectral/multiresolution remote sensing approach for disaggregation of surface soil moisture: Application to SMOS 
configuration. Ieee Transactions on Geoscience and Remote Sensing. 43 (9), 2036-2050.

Monteith, J.L. and Unsworth, M.H., 1990. Principles of Environmental Physics. Edward Arnold, London, 291 pp.

Moran, M.S., 2004. Thermal infrared measurement as an indicator of planet ecosystem health. Thermal remote sensing in land surface processes. D. Quattrochi, CRC - Taylor \& Francis. 257-282.

Moran, M.S., Humes, K.S. and Pinter, P.J., 1997. The scaling characteristics of remotely-sensed variables for sparsely-vegetated heterogeneous landscapes. Journal of Hydrology. 190 (3-4), 337-362.

Moran, M.S. et al., 1994. Use of Ground-Based Remotely-Sensed Data for SurfaceEnergy Balance Evaluation of a Semiarid Rangeland. Water Resources Research. 30 (5), 1339-1349.

Nakai, T., van der Molen, M.K., Gash, J.H.C. and Kodama, Y., 2006. Correction of sonic anemometer angle of attack errors. Agricultural and Forest Meteorology. 136 (1-2), 19-30.

Njoku, E.G., Hook, S.J. and Chehbouni, A., 1996. Effects of surface heterogeneity on thermal remote sensing of land parameters. In Scaling up in hydrology using remote sensing Chap. 2 In Scaling up in hydrology using remote sensing. Edited by J.B. Stewart, E.T. Engman, R.A. Feddes and Y. Kerr.

Noilhan, J., Lacarrere, P., Dolman, A.J. and Blyth, E.M., 1997. Defining area-average parameters in meteorological models for land surfaces with mesoscale heterogeneity. Journal of Hydrology. 190 (3-4), 302-316.

Norman, J.M. and Becker, F., 1995. Terminology in Thermal Infrared Remote-Sensing of Natural Surfaces. Agricultural and Forest Meteorology. 77 (3-4), 153-166.

Olioso, A. et al., 2005. Future directions for advanced evapotranspiration modeling: Assimilation of remote sensing data into crop simulation models and SVAT models. Irrigation and Drainage Systems. 19 (3-4), 377-412.

Paulson, C.A., 1970. The mathematical representation of wind speed and temperature profiles in the unstable atmospheric surface layer. Journal of Applied Meteorology. 9, 857-861.

Pelgrum, H. and Bastiaanssen, W.G.M., 1996. An intercomparison of techniques to determine the area-averaged latent heat flux from individual in situ observations: A remote sensing approach using the European Field Experiment in a Desertification-Threatened Area data. Water Resources Research. 32 (9), 2775-2786.

Porporato, A., Daly, E. and Rodriguez-Iturbe, I., 2004. Soil water balance and ecosystem response to climate change. Amer. Naturalist. 164, 625-632.

Raupach, M.R., 1991. Vegetation-Atmosphere Interaction in Homogeneous and Heterogeneous Terrain - Some Implications of Mixed-Layer Dynamics. Vegetatio. 91 (1-2), 105-120.

Raupach, M.R., 1993. The averaging of surface fluxes densities in heterogeneous landscapes. In H.J. Bolle, R.A. Feddes and J.D. Kalma (Editors), Exchange Processes at the land surface for a Range of Space and Time Scales, Proceedings of the Yokohama Symposuim, IAHS Publ. . 212, 334-355.

Raupach, M.R. and Finnigan, J.J., 1995. Scale Issues in Boundary-Layer Meteorology Surface-Energy Balances in Heterogeneous Terrain. Hydrological Processes. 9 $(5-6), 589-612$. 
Santanello, J.A. and Friedl, M.A., 2003. Diurnal covariation in soil heat flux and net radiation. Journal of Applied Meteorology. 42 (6), 851-862.

Schoups, G., Addams, C.L., Minjares, J.L. and Gorelick, S.M., 2006. Reliable conjunctive use rules for sustainable irrigated agriculture and reservoir spill control. Water Resources Research. 42 (12).

Seguin, B. and Itier, B., 1983. Using midday surface-temperature to estimate daily evaporation from satellite thermal IR data. International Journal of Remote Sensing. 4 (2), 371-383.

Sellers, P.J. et al., 1997. The impact of using area-averaged land surface properties Topography, vegetation condition, soil wetness - In calculations of intermediate scale (approximately $10 \mathrm{~km}(2)$ ) surface-atmosphere heat and moisture fluxes. Journal of Hydrology. 190 (3-4), 269-301.

Shaw, R.H. and Pereira, A.R., 1982. Aerodynamic roughness of a plant canopy: a numerical experiment. Agricultural and Forest Meteorology. 26, 51-65.

Shuttleworth, W.J., 1988. Macrohydrology- the new challenge for process hydrology. journal of Hydrology. 100, 31-56.

Shuttleworth, W.J. and Wallace, J.S., 1985. Evaporation from sparse crops - an energy combination theory. Quart. J. R. Meteorol. Soc. 111, 839-855.

Shuttleworth, W.J., Yang, Z.L. and Arain, M.A., 1997. Aggregation rules for surface parameters in global models. Hydrol. Earth Syst. Sci. 2, 217-226.

Stewart, J.B. et al., 1994. Sensible Heat-Flux Radiometric Surface-Temperature Relationship for 8 Semiarid Areas. Journal of Applied Meteorology. 33 (9), 1110-1117.

Stull, R.B., 1988. An Introduction to Boundary Layer Meteorology. Atmospheric Sciences Library, Kluwer Academic Publishers, Dordrecht, 666 pp.

Su, Z., 2002. The Surface Energy Balance System (SEBS) for estimation of turbulent heat fluxes. Hydrology and Earth System Sciences. 6 (1), 85-99.

Sugita, M. and Brutsaert, W., 1996. Optimal measurement strategy for surface temperature to determine sensible heat flux from anisothermal vegetation. Water Resources Research. 32 (7), 2129-2134.

Sugita, M. and Kubota, A., 1994. Radiometrically Determined Skin Temperature and Scalar Roughness to Estimate Surface Heat-Flux .2. Performance of Parameterized Scalar Roughness for the Determination of Sensible Heat. Boundary-Layer Meteorology. 70 (1-2), 1-12.

Sun, J. and Mahrt, L., 1995. Determination of surface fluxes from the surface radiative temperature. J. Atmos. Sci. 52, 1096-1106.

Troufleau, D., Lhomme, J.P., Monteny, B. and Vidal, A., 1997. Sensible heat flux and radiometric surface temperature over sparse Sahelian vegetation .1. An experimental analysis of the kB(-1) parameter. Journal of Hydrology. 189 (1-4), 815-838.

Twine, T.E. et al., 2000. Correcting eddy-covariance flux underestimates over a grassland. Agricultural and Forest Meteorology. 103 (3), 279-300.

van der Molen, M.K., Gash, J.H.C. and Elbers, J.A., 2004. Sonic anemometer (co)sine response and flux measurement - II. The effect of introducing an angle of attack dependent calibration. Agricultural and Forest Meteorology. 122 (1-2), 95-109. 
Verhoef, A., DeBruin, H.A.R. and VandenHurk, B., 1997. Some practical notes on the parameter $\mathrm{kB}(-1)$ for sparse vegetation. Journal of Applied Meteorology. 36 (5), 560-572.

Villalobos, F.J., Orgaz, F., Testi, L. and Fereres, E., 2000. Measurement and modeling of evapotranspiration of olive (Olea europaea L.) orchards. European Journal of Agronomy. 13 (2-3), 155-163.

Walker, J.P. and Houser, P.R., 2004. Requirements of a global near-surface soil moisture satellite mission: accuracy, repeat time, and spatial resolution. Advances in Water Resources. 27 (8), 785-801.

Wang, K.C., Li, Z.Q. and Cribb, M., 2006. Estimation of evaporative fraction from a combination of day and night land surface temperatures and NDVI: A new method to determine the Priestley-Taylor parameter. Remote Sensing of Environment. 102 (3-4), 293-305.

Watts, C.J. et al., 2000. Comparison of sensible heat flux estimates using AVHRR with scintillometer measurements over semi-arid grassland in northwest Mexico. Agricultural and Forest Meteorology. 105 (1-3), 81-89.

Wieringa, J., 1986. Roughness dependent geographical interpolation of surface wind speed averages. Quart. J. R. Meteorol. Soc. 112, 867-889. 


\section{TABLE CAPTIONS}

Table 1: Summary of vegetation, radiative properties and soil moisture conditions for the three adjacent fields during the study period.

\begin{tabular}{|c|c|c|c|}
\hline & chickpeas & cotton & wheat \\
\hline crop height $(\mathrm{m})$ & 0.50 & 0.25 & 2.50 \\
\hline LAI (-) & 0.50 & 0.15 & 0.18 \\
\hline albedo (-) & 0.22 & 0.2 & 0.98 \\
\hline emissivity (-) & 0.97 & 0.98 & 28 \\
\hline Mean soil moisture (\%) & 21 & 38 & 28 \\
\hline
\end{tabular}




\section{FIGURE CAPTIONS}

Figure 1: Location of the study site and overview of the irrigation disctrict

Figure 2: Experimental design.

Figure 3: Diurnal behavior (9:00 to 17:00) of Evaporative Fraction (EF) over the 3 sites during the study period.

Figure 4: Comparison between observed and simulated area-averaged sensible heat flux values at $14 \mathrm{~h} 00$. Observed $\mathrm{H}_{\mathrm{EC}}$ is obtained by area-averaging sensible heat flux measured over each individual field. Simulated values are obtained through the use of the Model ( $\mathrm{H}_{\text {Lhomme}}$ ) coupled to effective surface parameters derived from aggregation procedure.

Figure 5: Comparison between observed and simulated area-averaged available energy values at $14 \mathrm{~h} 00$. Observed $\mathrm{AE}_{\text {Meas }}$ is obtained by area-averaging available energy measured over each individual field. Simulated AEsim is obtained using aggregated values of surface parameters.

Figure 6: Comparison between area-averaged latent heat flux at $14 \mathrm{~h} 00$ derived from simulations and observations. Observed LE is obtained by area-averaging latent heat flux measured over each individual field. Simulated area-averaged LESim is computed as the residual of energy budget:

Figure 7: Comparison between diurnal courses of area-averaged evaporative fraction derived from simulations (Area-averaged simulated EF) and observations (Areaaveraged measured EF).

Figure 8: Comparison between diurnal course of area-averaged available energy derived from simulations (<AESim $>$ ) and observations (<AEMeas $>$ ). 
Figure 9: Scatter plot of area-averaged measured $\left(<\mathrm{LEEC}_{\mathrm{EC}}>\right)$ and simulated $(<\mathrm{LE}>)$ values for the diurnal course of latent heat flux. Simulations were obtained using EF parameterization along with AE measurements (dots). For illustration, the LE retrievals are also plotted when considering constant diurnal EF (crosses) rather than the proposed parameterization.

Figure 10: Scatter plot of area-averaged measured $\left(\left\langle\mathrm{LEEC}_{\mathrm{EC}}\right\rangle\right)$ and simulated $(<\mathrm{LEEF}$ Sim, AE Sim $>$ ) values for the diurnal course of latent heat flux. Simulations were obtained using EF and AE parameterizations. 


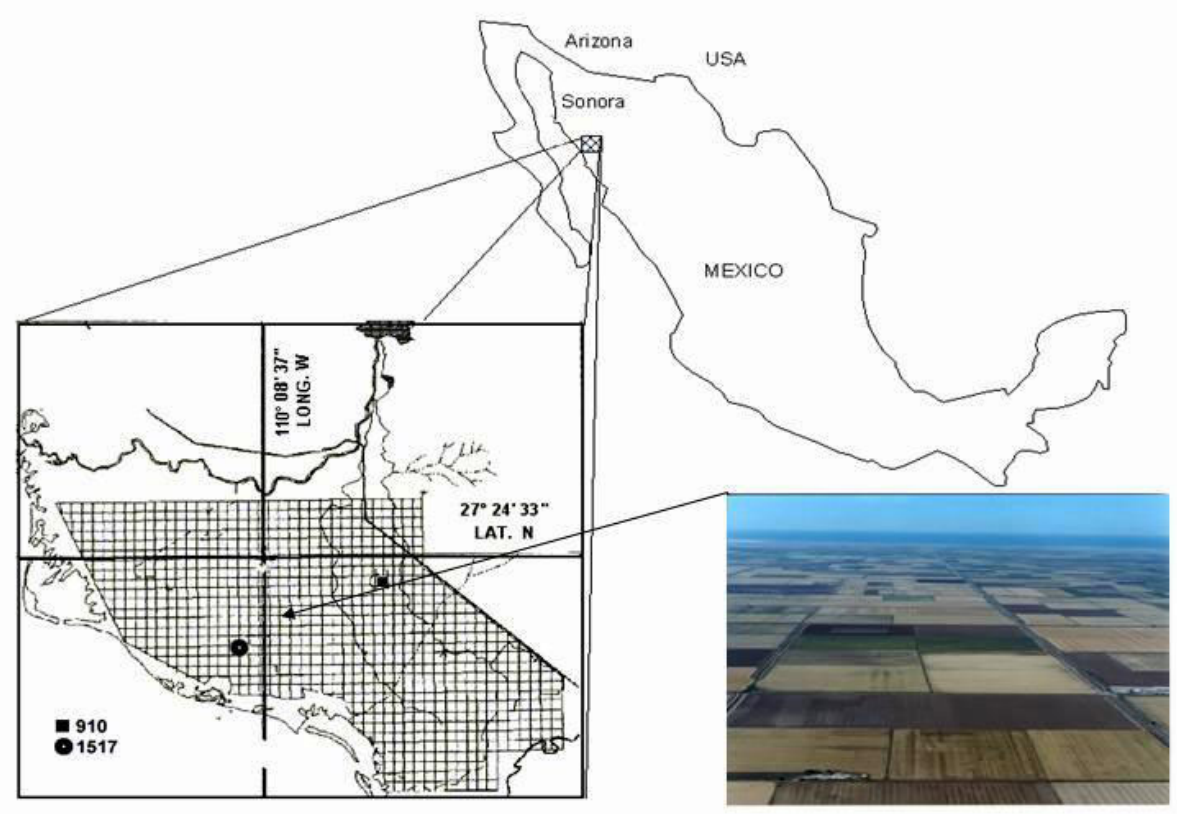

Figure 1 


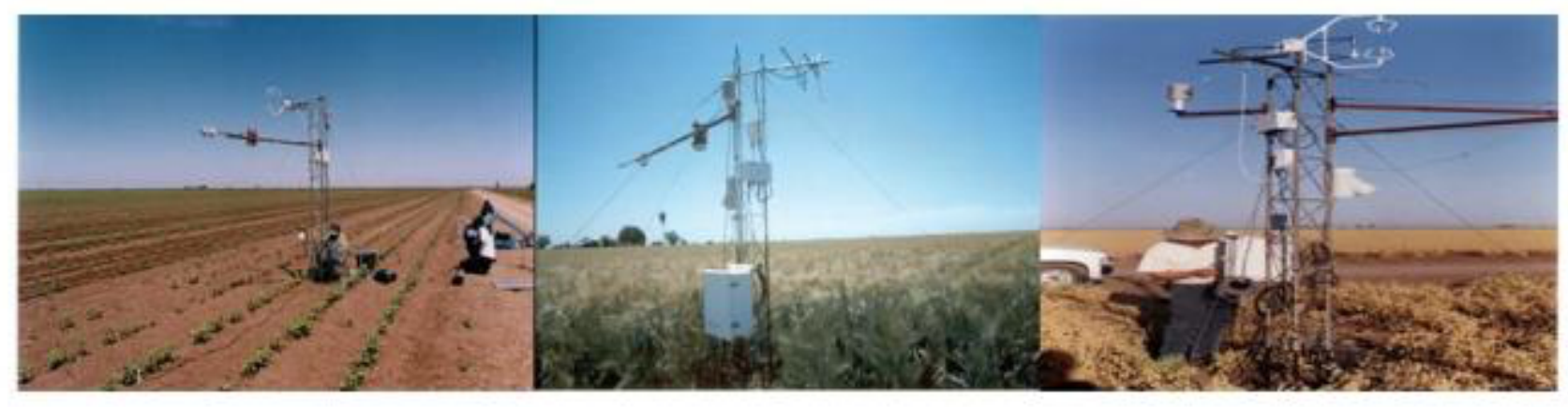

Figure 2 


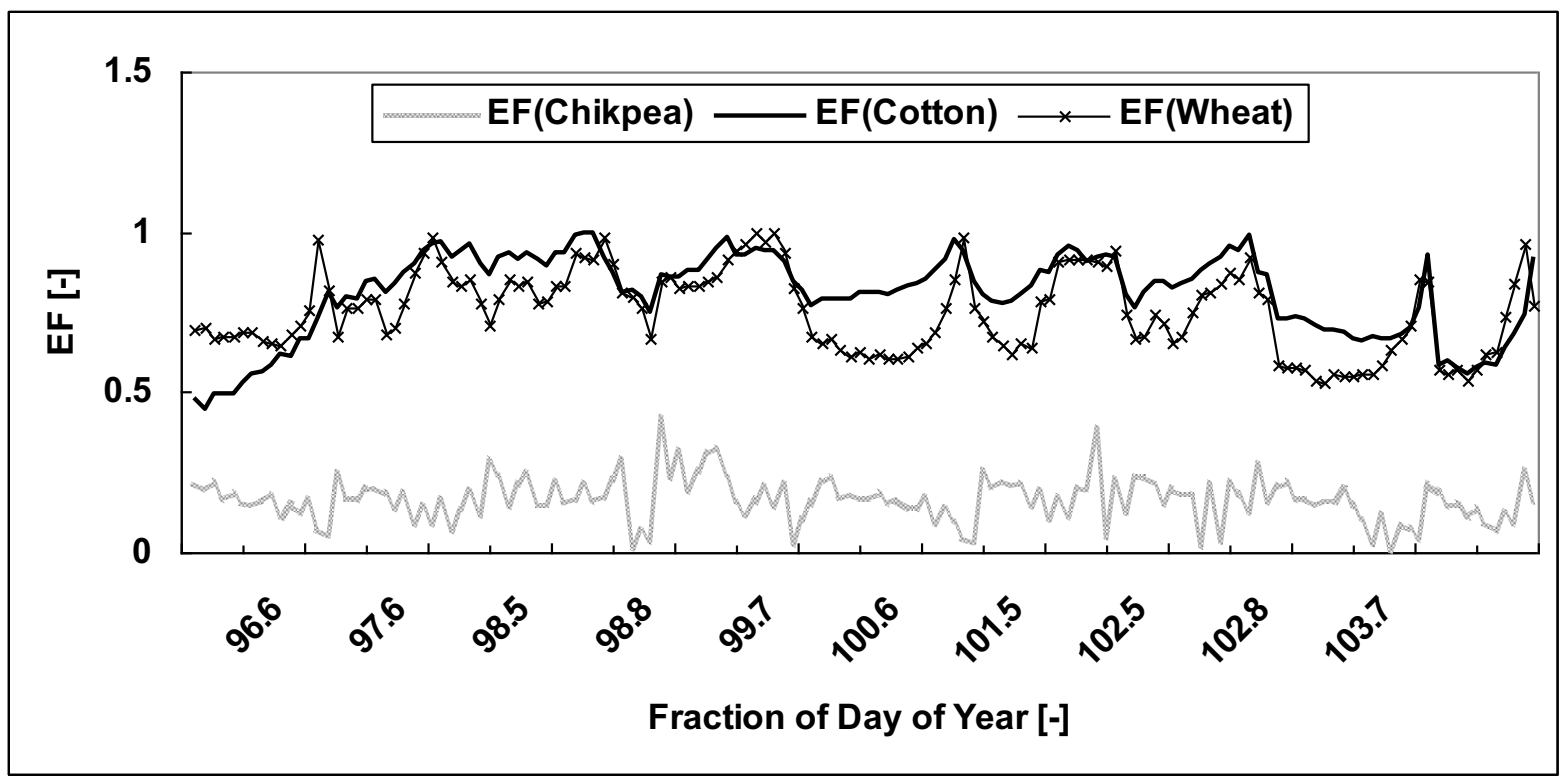

Figure 3 


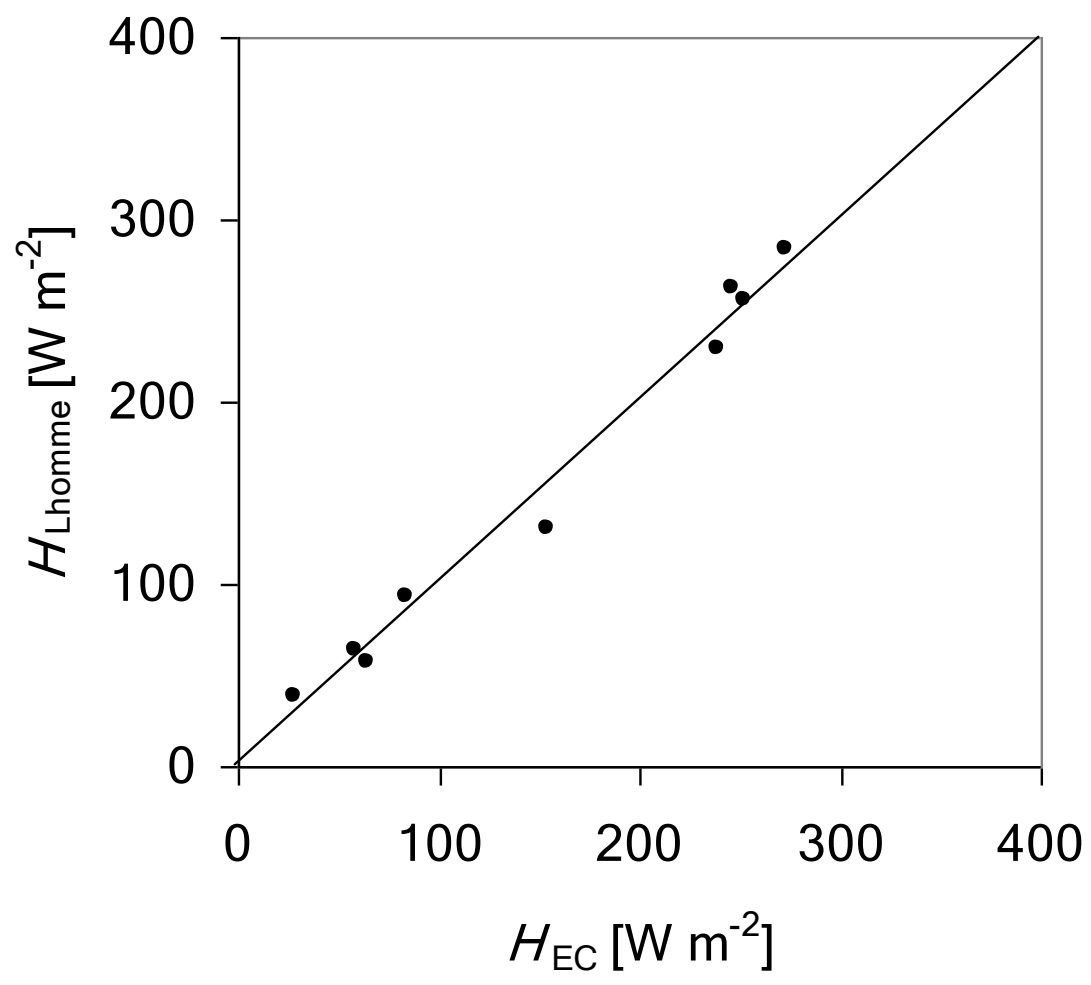

Figure 4 


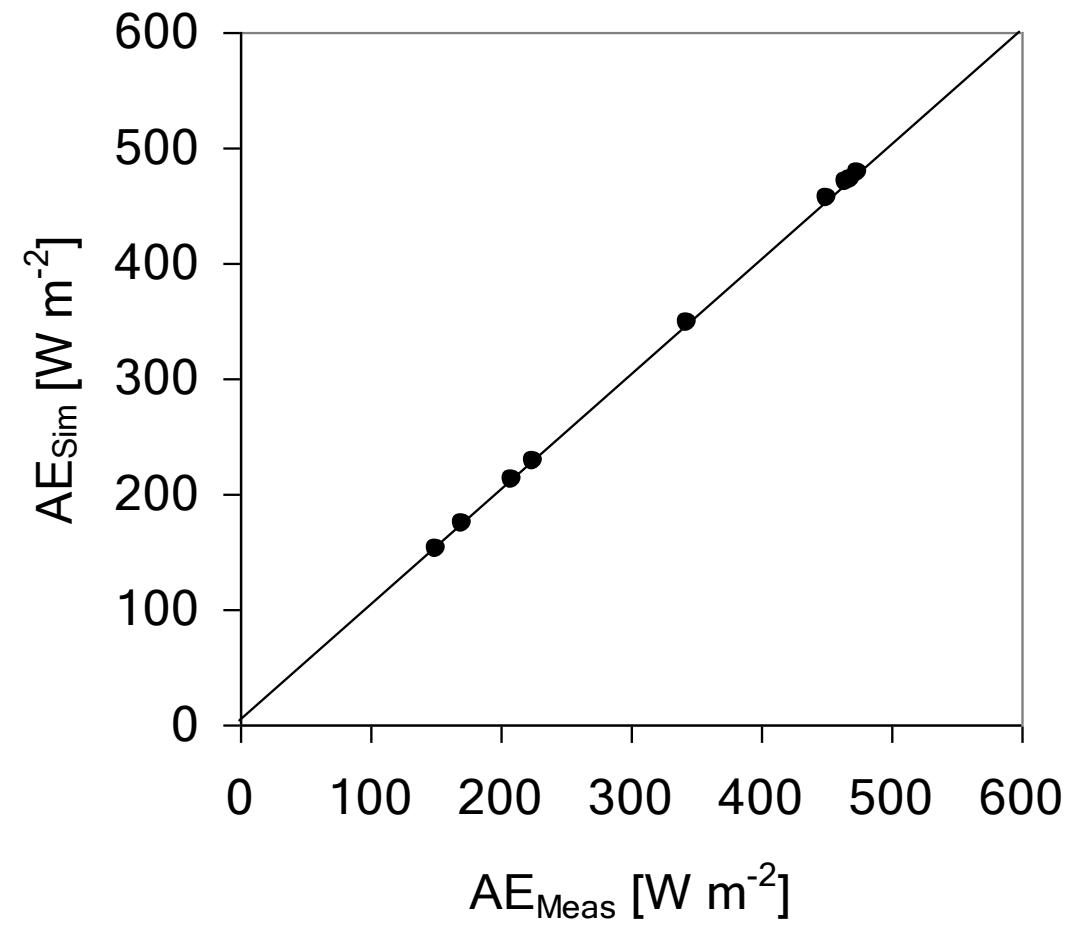

Figure 5 


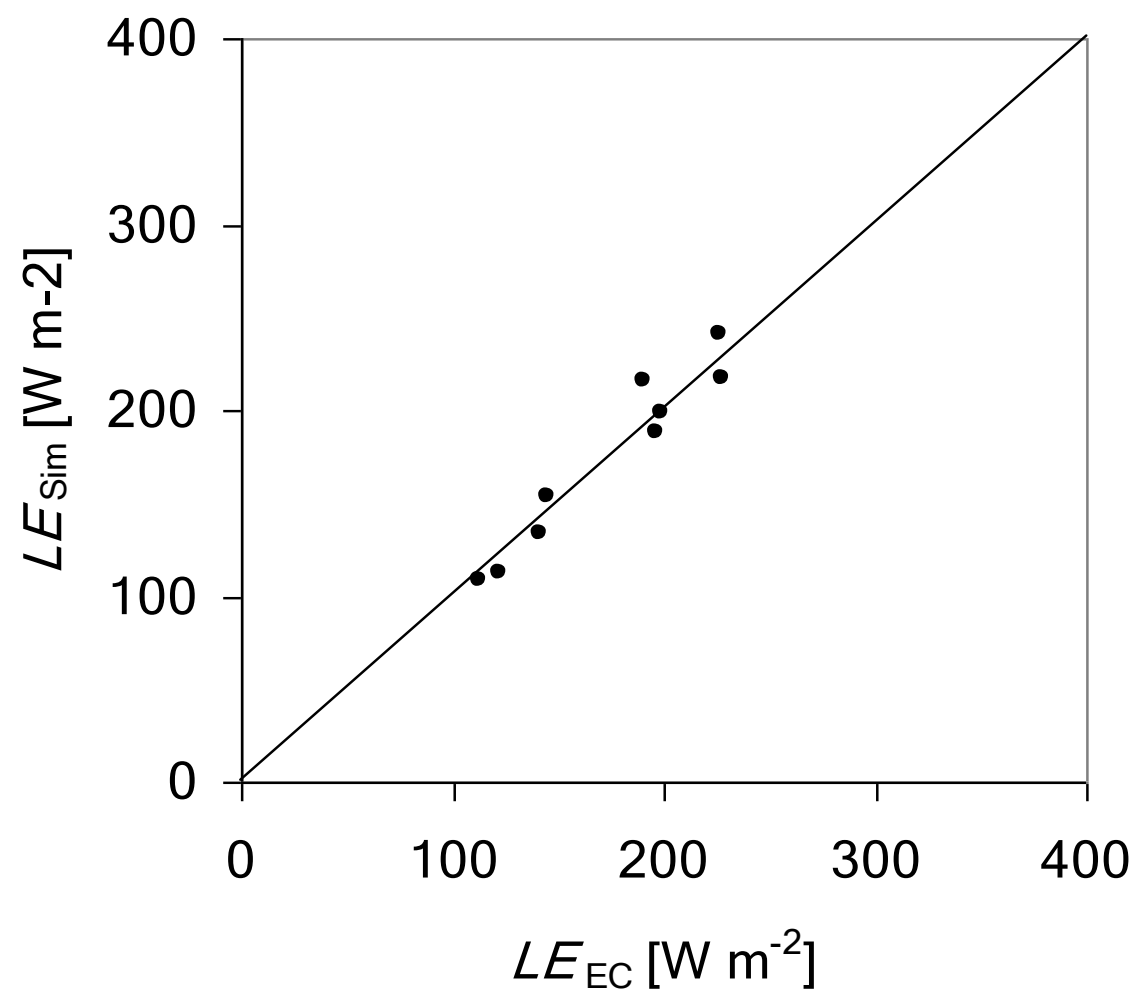

Figure 6 


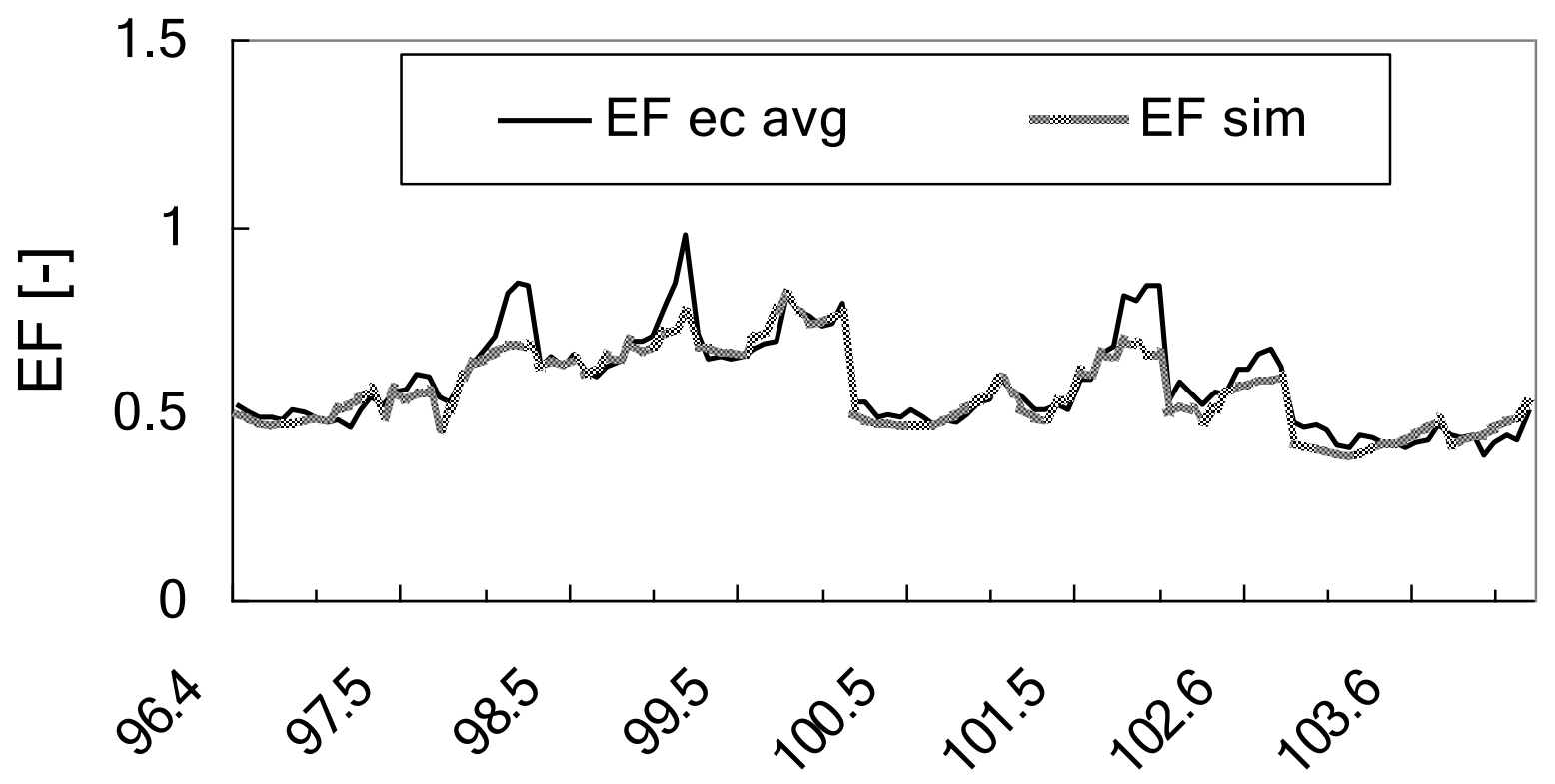

Fraction of the Day Of the Year [-]

Figure 7 


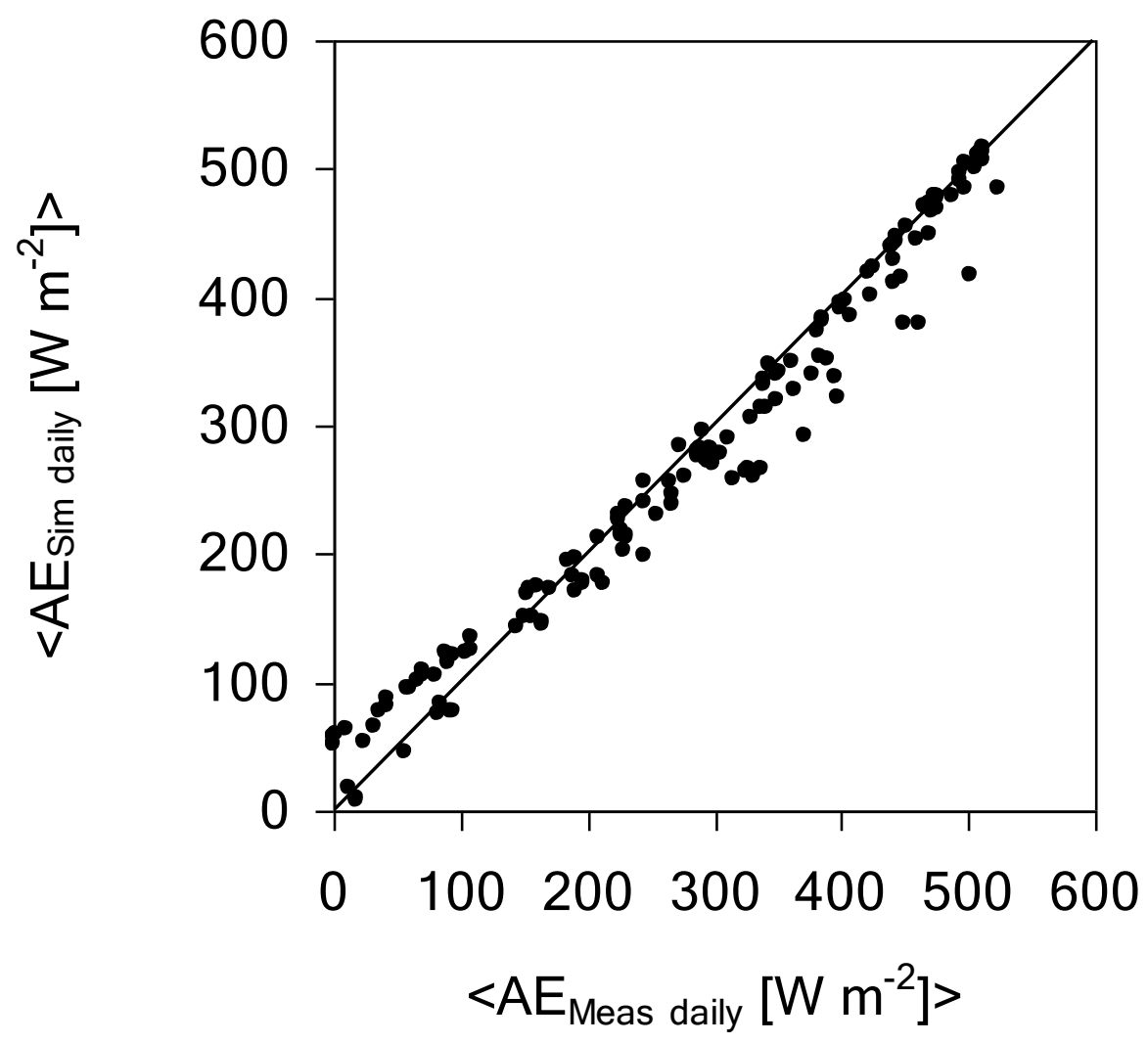

Figure 8 


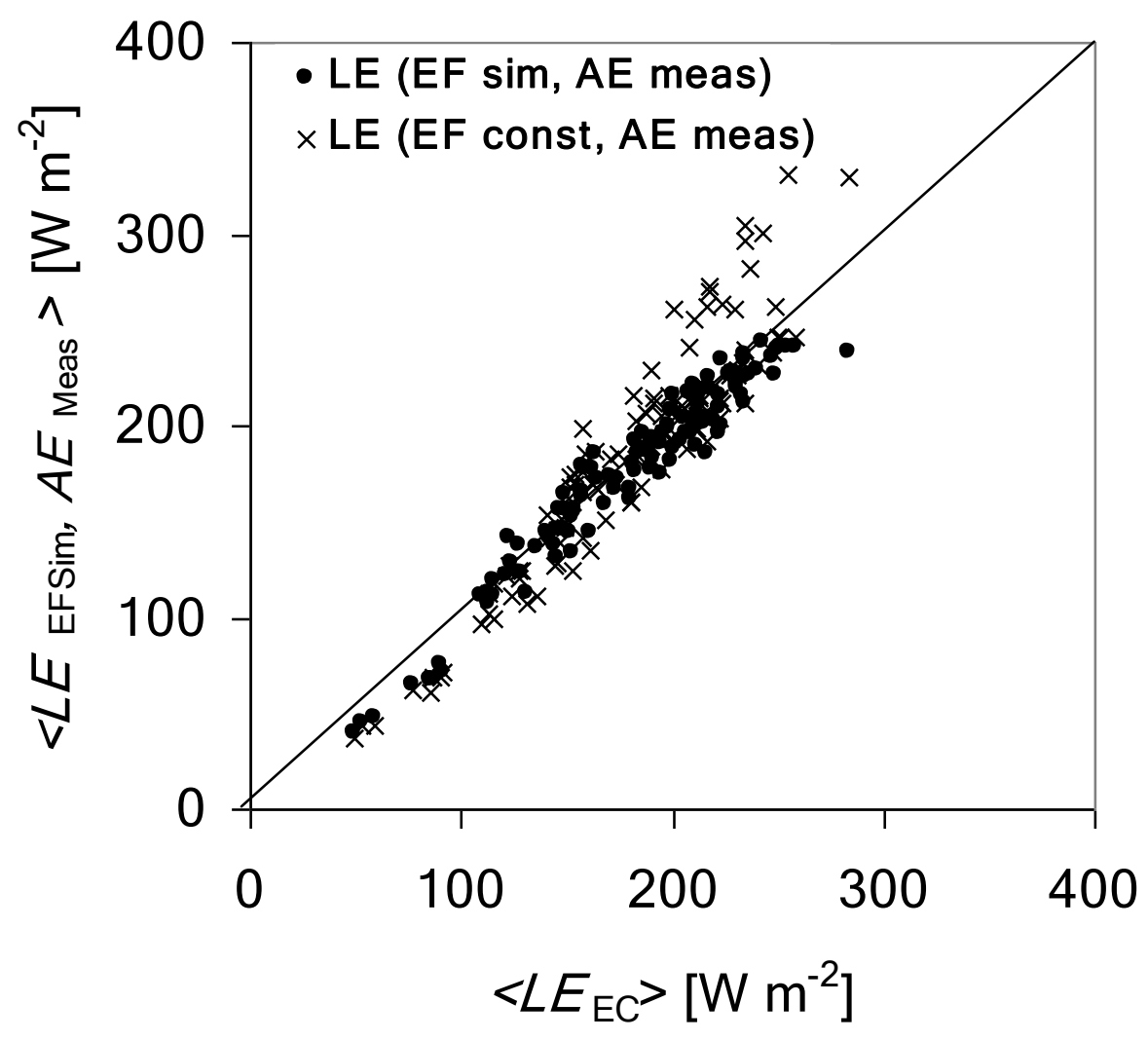

Figure 9 


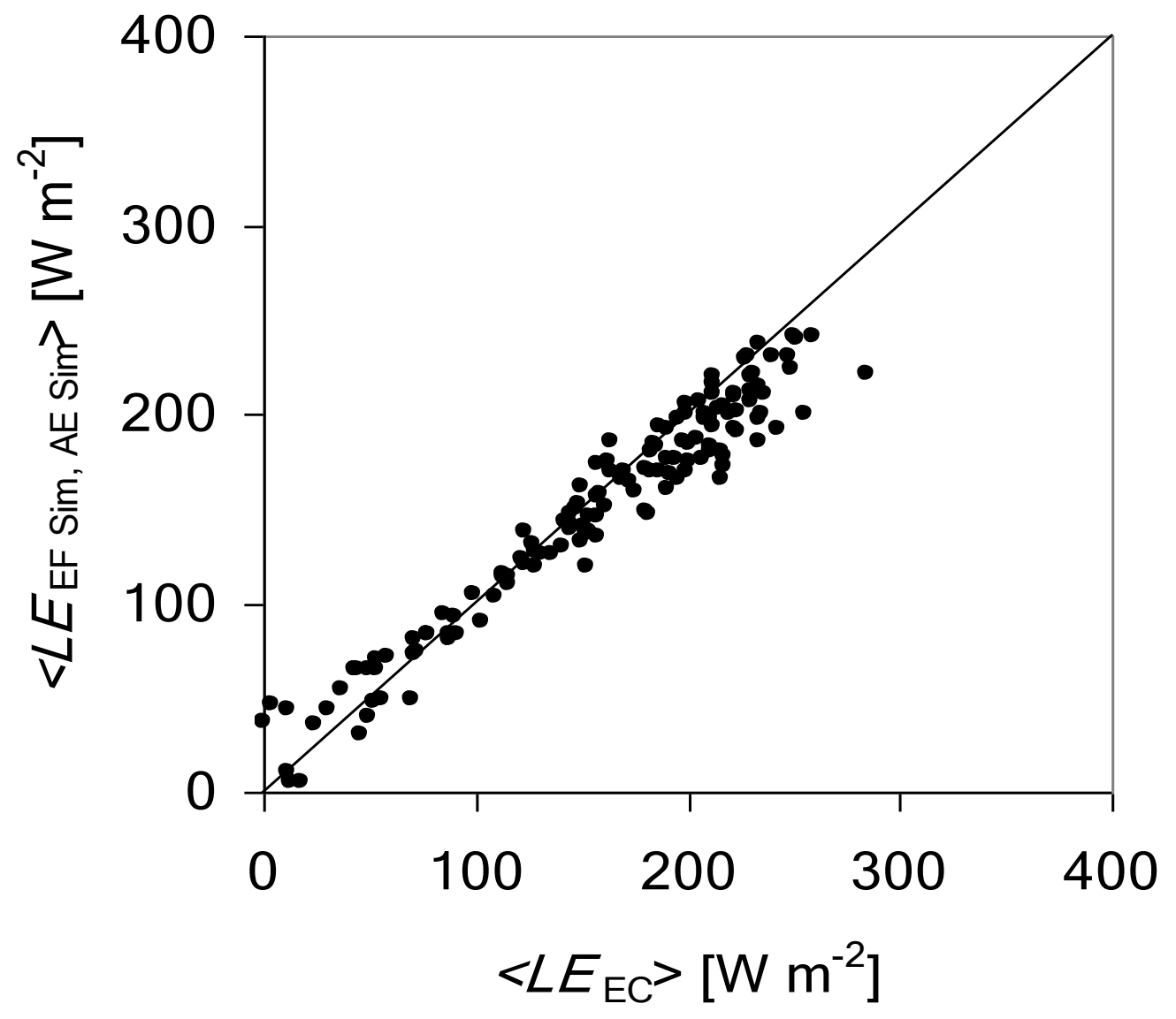

Figure 10 